\title{
Role of secretory leukocyte protease inhibitor in the development of subclinical emphysema
}

\author{
T. Betsuyaku*, K. Takeyabu*, M. Tanino*, M. Nishimura*
}

\begin{abstract}
Role of secretory leukocyte protease inhibitor in the development of subclinical emphysema. T. Betsuyaku, K. Takeyabu, M. Tanino, M. Nishimura. (C) ERS Journals Ltd 2002.

ABSTRACT: Secretory leukocyte protease inhibitor (SLPI) is a potent inhibitor of human leukocyte elastase. In some chronic airway diseases, the level of SLPI is decreased in sputum, leading to the continuation of neutrophil inflammation. In this study, the role of SLPI in subclinical pulmonary emphysema was examined.

Sequential bronchoalveolar lavage was performed in an attempt to separately evaluate the levels of SLPI in the large airways and in the peripheral airways for two groups of smokers. One group had subclinical emphysema by computed-tomography scans and one group did not. SLPI localized in alveolar macrophages (AM) was also assessed.

The level of SLPI was significantly elevated in the peripheral airways from the subjects with emphysema compared to those without emphysema $(1589.2 \pm 353.9$ versus $729.1 \pm$ $\left.31.0 \mathrm{ng} \cdot \mathrm{mL}^{-1}\right)$, although it was similar in the large airways $(3442.3 \pm 499.6$ versus $2535.7 \pm$ $\left.578.8 \mathrm{ng} \cdot \mathrm{mL}^{-1}\right)$. There was a trend for higher amount of SLPI to be released from AM in subjects with subclinical emphysema, although this did not reach statistical significance.

In conclusion, there is compensatory upregulation of secretory leukocyte protease inhibitor in peripheral airways in subclinical pulmonary emphysema, which is in sharp contrast to the decreased level of secretory leukocyte protease inhibitor reported in some chronic airway diseases.
\end{abstract}

Eur Respir J 2002; 19: 1051-1057.
*First Dept of Medicine, Hokkaido Uni-
versity School of Medicine, Sapporo and ${ }^{\#}$ Otaru Municipal Hospital, Otaru, Japan.

Correspondence: T. Betsuyaku, First Dept of Medicine, Hokkaido University School of Medicine, Kita 15 Nishi 7, Kita-ku, Sapporo 060-8638, Japan. Fax: 81117067899

E-mail: bytomoko@med.hokudai.ac.jp

Keywords: Alveolar macrophage

bronchoalveolar lavage

computed tomography

pulmonary emphysema

secretory leukocyte protease inhibitor

Received: June 152001

Accepted after revision January 8 2002
Secretory leukocyte protease inhibitor (SLPI), a $12-\mathrm{kDa}$ molecule, is also called antileukoprotease or mucous protease inhibitor and is believed to protect against proteolytic enzymes, especially neutrophilderived elastase [1]. SLPI is known to be located not only in serous cells of submucosal tracheal and bronchial glands [2], but also in nonciliated epithelial cells in the membranous/terminal bronchioli [3] and alveolar epithelial cells [4]. It was also reported that murine alveolar macrophages (AM) produce SLPI and that the level of SLPI messenger ribonucleic acid (mRNA) expression is a determinant of speciesrelated variation in the susceptibility to lipopolysaccharide (LPS)-induced lung injury [5]. The concentrations of SLPI in biological samples have been monitored to correlate them with pathological conditions. An increase in the level of SLPI has been reported in sera from patients with pneumonia $[6,7]$ and adult respiratory distress syndrome [8], and in sputum from patients with cystic fibrosis [9]. In contrast, the level of SLPI is reported to be decreased in bronchial fluid from patients with diffuse panbronchiolitis [10] and in sputum from patients with chronic bronchitis [11], which might lead to neutrophil elastase (NE)-dominant chronic inflammation in airways.

The involvement of SLPI in pulmonary emphysema has been speculated because an electron-microscopic study revealed that SLPI is associated with elastic fibres in lung parenchyma [12], and because SLPI is able to gain access to the microenvironment because of its small molecular size [13]. Animal studies have also demonstrated the protective role of SLPI in the development of pulmonary emphysema. Administration of recombinant SLPI has been reported to be effective in preventing lung destruction in animal models of emphysema [14]. Interferon- $\gamma$ transgenic mice develop spontaneous emphysema accompanied by downregulation of SLPI mRNA in the lungs [15]. Consequently, SLPI is thought to have an important role in maintaining the protease-antiprotease balance in the lung parenchyma as well as the airways.

In this study, SLPI concentrations in large and peripheral airways in patients with and without subclinical emphysema were determined. It was then established whether SLPI was released from AM and whether the levels of SLPI mRNA in AM were linked to the intersubject susceptibility in smoking-induced lung destruction in humans.

\section{Methods and materials}

\section{Subjects}

A total of 48 volunteers (aged $32-80 \mathrm{yrs}$ ) were recruited and informed consent was obtained from each subject, including 32 current-smokers and 16 
exsmokers. There were no never-smokers. The subjects had no respiratory symptoms or comorbidties, and had been free of acute respiratory infections within the preceding 2 months. Blood tests were performed and none of the subjects $\alpha_{1}$-antitrypsin serum levels $<160 \mathrm{mg} \cdot \mathrm{dL}^{-1}$. Pulmonary function tests, including vital capacity (VC), forced expiratory volume in one second (FEV1), and carbon monoxide diffusing capacity of the lung were performed (CHESTAC-55V; Chest Co, Tokyo, Japan). Highresolution computed-tomography (CT) scans were performed to screen for emphysematous changes [16]. Briefly, three pulmonary physicians, who were blind to any information about individual patients, independently evaluated the presence of emphysematous changes in all horizontal slices on CT scans. The subjects were defined as emphysema $(+)$, regardless of the magnitude or severity of disease, on the basis of agreement of all three physicians. All other subjects were defined as emphysema (-). The Ethics Committee of Hokkaido University School of Medicine approved the study.

\section{Sequential bronchoalveolar lavage}

The smokers were asked to refrain from smoking for at least $12 \mathrm{~h}$ prior to a bronchoalveolar lavage (BAL) procedure to remove the acute effect of smoking. Sequential BAL was performed using a modification of the technique introduced by RENNARD et al. [17] in an attempt to separately collect materials from large airways and from peripheral airways. In brief, four separate $50-\mathrm{mL}$ aliquots of sterile $0.9 \%$ saline were instilled into the right middle lobe segment of the lungs through a wedged flexible fibreoptic bronchoscope (Olympus BF-B3R; Olympus, Tokyo, Japan), and then were gently suctioned. The fluid returned from the first $50-\mathrm{mL}$ aliquot was used as bronchial lavage (BL) fluid containing cells and materials from the large airways rather than the peripheral regions. The remaining lavage fluid was pooled and used as BAL fluid. Recovered BL fluid and BAL fluid were filtered separately through several layers of gauze to remove excess mucus and debris and then centrifuged at $1,500 \mathrm{rpm}$ for $5 \mathrm{~min}$ at $4{ }^{\circ} \mathrm{C}$ to separate the supernatant from the cells. Cell analyses were carried out for each individual as previously described [16]. Cell-free supernatant was aliquated and stored at $-70^{\circ} \mathrm{C}$ until use.

\section{Culture of alveolar macrophages}

Lavaged AM were isolated and cultured as previously described [18]. Briefly, AM were adjusted to $1 \times 10^{6} \mathrm{AM} \cdot \mathrm{mL}^{-1}$ and isolated by adherence onto polyL-lysine-coated plastic wells (Corning, NY, USA) for $1 \mathrm{~h}$ at $37^{\circ} \mathrm{C}$ in Roswell Park Memorial Institute (RPMI)-1640 medium (GIBCO, Grand Island, NY, USA). After removal of nonadherent cells by two washes in phosphate-buffered saline, the remaining cells were cultured in RPMI-1640 medium for an additional $24 \mathrm{~h}$. In five random cases, AM were cultured in the presence of cycloheximide $(\mathrm{CHX})$ at $0.5 \mu \mathrm{g} \cdot \mathrm{mL}^{-1}$.

Enzyme-linked immunosorbent assay of secretory leukocyte protease inhibitor in bronchial lavage fluid and bronchoalveolar lavage fluid

The levels of SLPI in the BL fluid and BAL fluid were determined using enzyme-linked immunosorbent assay (ELISA) kits, which were gifts from Teijin Iyaku Co (Tokyo, Japan). The ELISA detects the active sites of SLPI molecules in a sample [7]. A standard curve was obtained with serial dilution of the supplied recombinant human SLPI by linear regression and the minimal detection limit was $6.25 \mathrm{ng} \cdot \mathrm{mL}^{-1}$. The concentration of SLPI in each sample was obtained by interpolation of its absorbance from the standard curve, and the mean value of duplicate samples was then taken as the representative value. For normalization, the albumin concentrations in BL fluid and BAL fluid were measured as previously described [16].

Enzyme-linked immunosorbent assay of secretory leukocyte protease inhibitor in alveolar macrophage culture medium

To detect pg levels of SLPI as opposed to ng levels in the culture medium of AM, a sensitive ELISA kit (Quantikine; Research \& Diagnositics, Minneapolis, MN, USA), utilizing a monoclonal antibody specific for SLPI was used. The detection limit of this kit was $9 \mathrm{pg} \cdot \mathrm{mL}^{-1}$. No cross-reactivity with cytokines, growth factors, elastase, trypsin, and chymotrypsins was verified according to the protocol provided with the kit.

\section{Western-blot analysis}

BAL fluid was concentrated using Centricon filters having a molecular weight cut-off of 10,000 (Amicon Inc., Beverly, MA, USA). Fifteen-fold concentrated BAL fluids $(20 \mu \mathrm{L})$ were denatured and reduced in the presence of 2-mercaptoethanol $(1.25 \%)$. The samples were then electrophoresed on a $15 \%$ sodium dodecylsulphate-polyacrylamide gel and transferred to polyvinylidene diflouride membranes (Millipore, Bedford, MA, USA). Nonspecific binding sites were blocked with Tris-buffered saline-containing $0.1 \%$ Tween 20 (TBS-T) and 5\% nonfat dried milk for $12 \mathrm{~h}$ at $4{ }^{\circ} \mathrm{C}$. For analysis of SLPI proteins, membranes were incubated in $10 \mu \mathrm{g} \cdot \mathrm{mL}^{-1}$ of a rabbit polyclonal antihuman SLPI antibody (a gift from Teijin Iyaku Co.) in TBS-T. After three washes in TBS-T, membranes were incubated in a 1:4000 dilution of horseradish peroxidase-conjugated goat serum anti-rabbit immunoglobulin-G (Amersham, Aylesbury, UK). The SLPI immunoreactivity was visualized using an enhanced chemiluminescence Western blotting analysis system (Amersham). Two-hundred ng of recombinant SLPI was used as a positive control (a gift from Teijin Iyaku Co.). 
Quantitative reverse transcriptase-polymerase chain reaction for secretory leukocyte protease inhibitor

Total ribonucleic acid (RNA) was purified from AM with guanidium thicyanate using an Isogen RNA extraction kit (Nippon Gene, Tokyo, Japan). Reverse transcriptase (RT) was carried out in the presence of Maloney leukaemia virus (M-MLV) RTase (Epicentre Technologies, Madison, WI, USA) and $5^{\prime}$ exonuclease-based fluorogenic polymerase chain reaction (PCR) was performed using an ABI PRISM 7700 Sequence Detector (PE Applied Biosystems, Foster City, CA, USA) as described previously [19]. Oligonucleotide SLPI primers for SLPI were derived from exon 2 and exon 3 of the human SLPI gene sequence [20]. The primers and probe for this quantification system were designed to meet specific criteria by using Primer Express software (PE Applied Biosystems) as follows: sense-primer: 5'-TGGCATCAAATGCCTGGAT-3'; antisenseprimer: 5'-TGGGCACTTCCCAGGCT-3'; probe: 5'-FAM-TGACACCCCAAACCCAACAAGGAGGTAMRA-3'.

The predicted size of the amplified SLPI deoxyribonuceic acid (DNA) product was $66 \mathrm{bp}$, and the specific amplification was confirmed by ethidium bromide staining of the PCR product on an agarose gel. Primers and a labelled probe for glyceraldehyde-3phosphatase-dehydrogenase (GAPDH) complementary DNA as an endogenous control were purchased from PE Applied Biosystems (TaqMan GAPDH control reagents). The relative amount of SLPI mRNA in the samples was normalized by GAPDH mRNA.

\section{Statistical analysis}

All values are expressed as mean \pm SEM. Data were analysed with paired or unpaired t-tests for comparison of two groups. Differences were considered to be significant when $\mathrm{p}<0.05$.

\section{Results}

\section{Characteristics of the subjects}

Clinical characteristics and pulmonary function data for the subjects whose BAL fluids were assayed for the levels of SLPI are summarized in table 1. All the subjects were categorized into two groups with or without emphysematous changes on $\mathrm{CT}$ scans regardless of smoking history. There were no significant differences in age or pack-yrs of smoking between the two groups. Pulmonary function data revealed that \% FEV1, FEV1/forced vital capacity (FVC), and $\%$ carbon monoxide diffusing capacity of the lung $(\mathrm{DL}, \mathrm{CO}) /$ alveolar volume $(\mathrm{VA})$ were significantly lower in the emphysema (+) group than in the emphysema (-) group. BL and BAL findings are shown in table 2. The total recovery rate was slightly but significantly lower in the emphysema $(+)$ group. There was no difference in the percentage of macrophages and
Table 1.-Subject characteristics

\begin{tabular}{lcc}
\hline & Emphysema (-) & Emphysema (+) \\
\hline Subjects n (f) & $14(1)$ & $13(0)$ \\
Smoking status & $6 / 8$ & $7 / 6$ \\
$\quad$ noncurrent/current & $56 \pm 3$ & $58 \pm 4$ \\
Age yrs & $28 \pm 6$ & $40 \pm 3$ \\
Pack-yrs of smoking & $118 \pm 3$ & $109 \pm 3$ \\
VC \% pred & $116 \pm 5$ & $93 \pm 5^{*}$ \\
FEV1\% pred & $80 \pm 1$ & $73 \pm 3^{*}$ \\
FEV1/FVC \% & $92 \pm 4$ & $73 \pm 4^{*}$ \\
DL,CO/VA \% pred &
\end{tabular}

Data are presented as mean \pm SE unless otherwise stated. f: female; VC: vital capacity; FEV1: forced expiratory volume in one second; FVC: forced vital capacity; $D$ L,CO: carbon monoxide diffusing capacity of the lung; $V \mathrm{~A}$ : alveolar volume. *: $\mathrm{p}<0.05$ compared to emphysema (-).

neutrophils both in BL and BAL fluid between the two groups.

Secretory leukocyte protease inhibitor in bronchial lavage fluid and in bronchoalveolar lavage fluid

Twenty-seven samples of BAL fluid and 20 samples of BL fluid were assayed for SLPI. The mean value of the SLPI concentration in BAL fluid from the emphysema $(+)$ subjects was significantly higher than for the emphysema (-) subjects (1589.2 \pm 353.9 versus $729.1 \pm 31.0 \mathrm{ng} \cdot \mathrm{mL}^{-1}, \mathrm{p}<0.05$ ) (fig. 1). In contrast, the SLPI concentration in BL fluid did not differ between the two groups $(3442.3 \pm 499.6$ versus $2535.7 \pm$ $\left.578.8 \mathrm{ng} \cdot \mathrm{L}^{-1}, \mathrm{NS}\right)$. After normalization to albumin, a significant difference of the levels of SLPI in BAL fluid between the two groups remained $(42.2 \pm 11.5$ versus $19.2 \pm 1.3 \mathrm{ng} \cdot \mathrm{mg}^{-1}$ albumin, $\mathrm{p}<0.05$ ) (fig. 2), but no difference between these groups was found in BL fluid $\left(107.5 \pm 20.8\right.$ versus $102.0 \pm 36.9 \mathrm{ng} \cdot \mathrm{mg}^{-1}$ albumin, NS).

Table 2.-Characteristics of bronchial lavage (BL) fluid and bronchoalveolar lavage (BAL) fluid

\begin{tabular}{lcc}
\hline & $\begin{array}{c}\text { Emphysema } \\
(-)\end{array}$ & $\begin{array}{c}\text { Emphysema } \\
(+)\end{array}$ \\
\hline Total recovery rate $\%$ & $52 \pm 2$ & $41 \pm 3^{*}$ \\
BL fluid & 7 & 13 \\
$\quad$ Subjects n & $86 \pm 2$ & $79 \pm 5$ \\
Macrophages \% & $3.4 \pm 1.2$ & $4.5 \pm 1.5$ \\
Neutrophils \% & $41 \pm 5$ & $32 \pm 3$ \\
Albumin $\mu \mathrm{g} \cdot \mathrm{mL}^{-1}$ & & \\
$\quad$ in BL fluid & 14 & 13 \\
BAL fluid & $23 \pm 3$ & $24 \pm 9$ \\
Subjects & & \\
Total cells $\times 10^{4} \cdot \mathrm{mL}^{-1}$ & $90 \pm 2$ & $87 \pm 2$ \\
$\quad$ in BAL fluid & $92 \pm 1$ & $91 \pm 2$ \\
$\quad$ Viability of the cells \% & $0.7 \pm 0.1$ & $1.3 \pm 0.3$ \\
Macrophages \% & $39 \pm 3$ \\
Neutrophils \% & & \\
Albumin $\mu \mathrm{g} \cdot \mathrm{mL}^{-1}$ in & $39 \pm 4$ & \\
$\quad$ BAL fluid & & \\
\hline
\end{tabular}

Data are presented as mean \pm SE unless otherwise stated. \#: ((BL fluid+BAL fluid)/200 mL) $\times 100 .{ }^{*}$ : $\mathrm{p}<0.05$ compared with emphysema (-). 


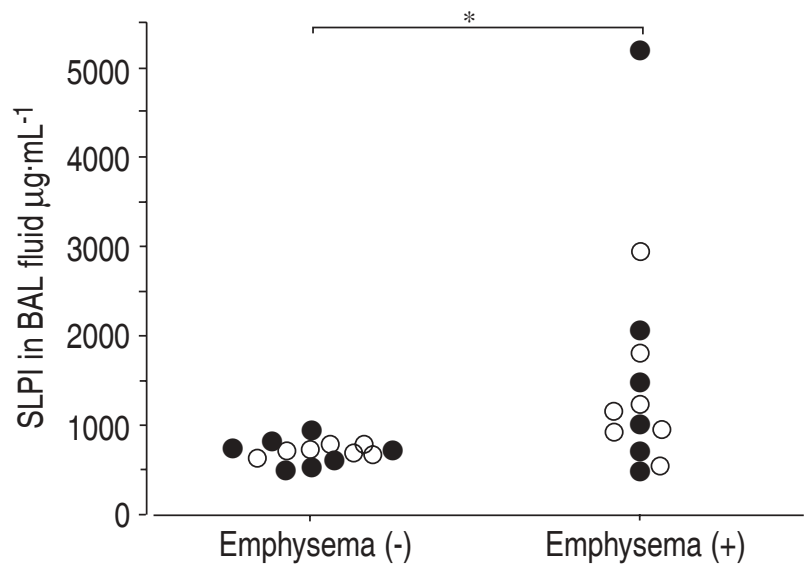

Fig. 1.-Secretory leukocyte protease inhibitor (SLPI) concentrations in broncoalveolar lavage (BAL) fluid in subjects with emphysema $(+)$ or without (-). ○: exsmoker; ๑: current-smoker. $*: \mathrm{p}<0.05$.

\section{Western blotting}

To determine the molecular state of SLPI present in BAL fluid, Western blot analysis was carried out using an antihuman SLPI polyclonal antibody. SLPI was present in intact form as a $12-\mathrm{kDa}$ band in BAL fluid from all the subjects. A slightly lower molecular weight band detected in a subject with emphysema was thought to be a degradation product of SLPI (fig. 3).

Release of secretory leukocyte protease inhibitor from alveolar macrophages

A sensitive ELISA, was employed to detect SLPI released from AM. AM from 31 consecutive subjects were analysed. There was a trend for a higher amount of SLPI to be released from AM in emphysema (+) subjects compared to emphysema (-) subjects, although

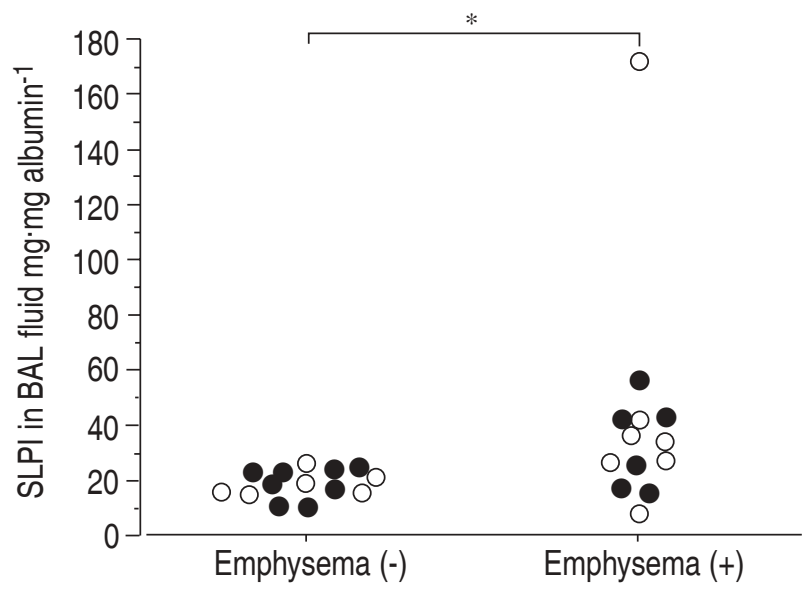

Fig. 2. - Secretory leukocyte protease inhibitor (SLPI) levels were expressed relative to the concentrations of albumin in bronchoalveolar lavage (BAL) fluid in subjects with emphysema $(+)$ or without (-). $\bigcirc$ : exsmoker; $\bullet$ : current-smoker. ${ }^{*}$ : $p<0.05$.

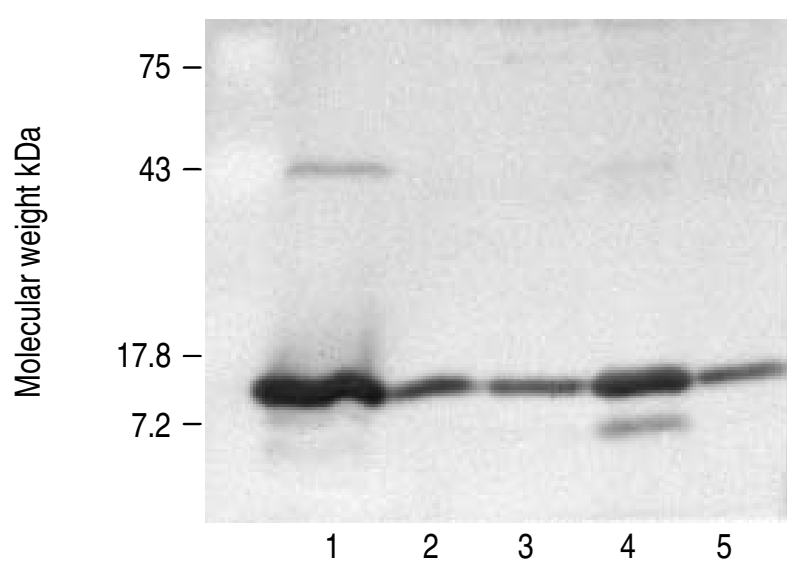

Fig. 3.-Western blotting of secretory leukocyte protease inhibitor (SLPI) in broncoalveolar lavage (BAL) fluid from two representative current-smokers without emphysema and two current-smokers with emphysema. Lane 1: positive control (200 ng recombinant SLPI); Lanes 2 and 3: concentrated BAL fluid samples of currentsmokers without emphysema; Lanes 4 and 5: concentrated BAL fluid samples of current-smokers with emphysema.

this did not reach conventional statistical significance (164.4 \pm 46.0 versus $57.9 \pm 10.7 \mathrm{pg} \cdot \mathrm{mL}^{-1}, \mathrm{p}=0.08$ ) (fig. 4).

Effect of cycloheximide on the release of secretory leucocyte protease inhibitor

For five randomly selected subjects, the effect of $\mathrm{CHX}$ on the release of SLPI was tested. The release was not inhibited by co-culture with $\mathrm{CHX}$ at $0.5 \mu \mathrm{g} \cdot \mathrm{mL}^{-1}$, indicating that the release of SLPI was not dependent on the new synthesis of protein in vitro for $24 \mathrm{~h}$ (fig. 5).

Secretory leukocyte protease inhibitor messenger ribonucleic acid levels in alveolar macrophages

A 5' onuclease-based fluorogenic RT-PCR was performed to assess the SLPI gene expression

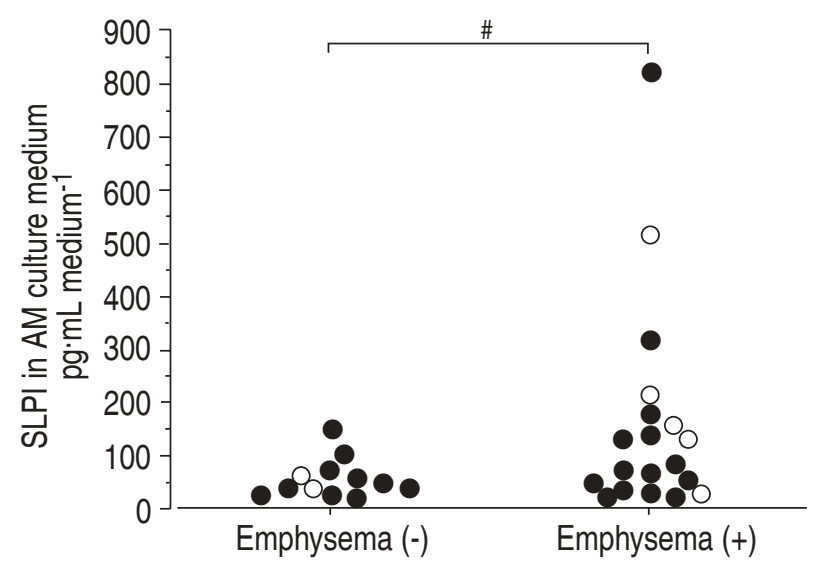

Fig. 4.-Concentration of secretory leukocyte protease inhibitor (SLPI) in the supernatant of alveolar macrophage (AM) culture medium in subjects with emphysema $(+)$ or without $(-)$. $\bigcirc$ : exsmoker; : current-smoker. ${ }^{\#}$ : NS. 


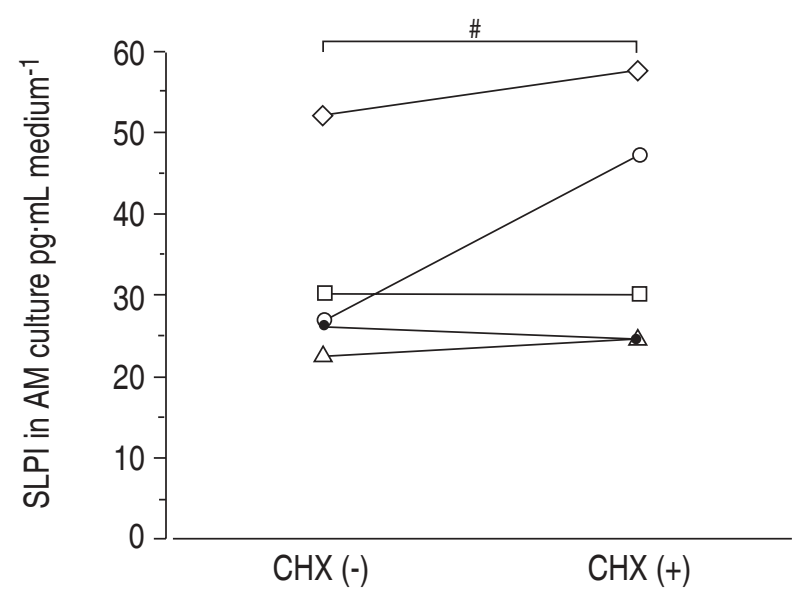

Fig. 5.-Secretory leukocyte protease inhibitor (SLPI) release from alveolar macrophages (AM) in the absence (CHX (-)) or presence $(\mathrm{CHX}(+))$ of cycloheximide $(\mathrm{CHX}) .{ }^{\#}$ : NS.

quantitatively in AM from 17 of the 31 subjects whose AM were analysed for the releaseability of SLPI. Figure 6 shows that SLPI mRNA was present in AM. The magnitude of SLPI mRNA expression corrected by GAPDH transcripts did not differ either in the absence or presence of emphysema $(0.7 \pm 0.5$ versus $0.5 \pm 0.2, \mathrm{p}=0.8$ ) (fig. 6). There was no relationship between the level of SLPI released from AM and mRNA of SLPI in AM.

\section{Discussion}

Firstly, it has been demonstrated in this study that SLPI concentrations were similar in the large airways but increased in the peripheral airways in patients with subclinical emphysema. Secondly, evidence that human AM actually contain SLPI was provided, as a significant amount of SLPI in $24 \mathrm{~h}$ cultured medium of AM was found and SLPI mRNA could be detected in AM from all the subjects examined. However, the level of SLPI mRNA in AM was not linked to the intersubject susceptibility to smoking-induced lung destruction.

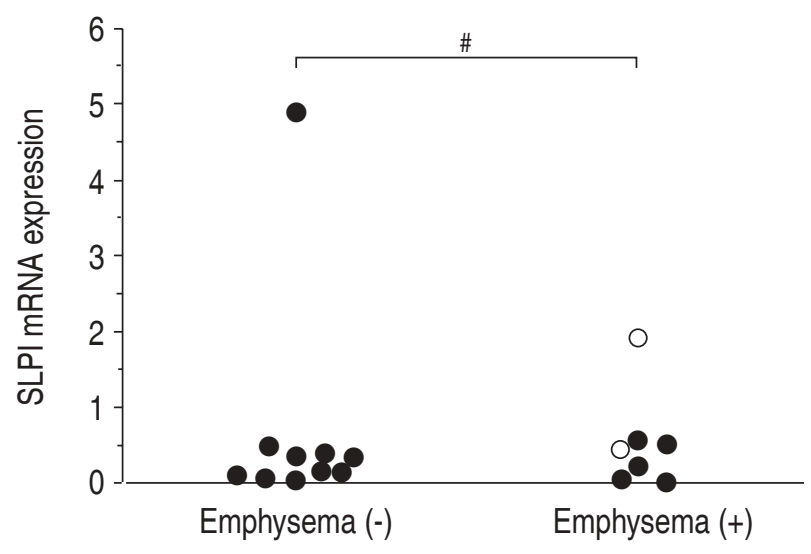

Fig. 6.-Secretory leukocyte protease inhibitor (SLPI) messenger ribonucleic acid levels in alveolar macrophages in subjects with emphysema (+) or without (-). $\bigcirc$ : exsmoker; : current-smoker. ${ }^{\#}$ : NS.
The results of this study clearly differ from some previous studies, which demonstrated that the level of SLPI was decreased in bronchial fluid from patients with diffuse panbronchiolitis [10] and in sputum from patients with chronic bronchitis [11]. The discrepancy between those studies and the current study may be explained by the difference in the stage of disease and/or the predominant site of disease. The subjects in this study were in the early stage of pulmonary emphysema and did not have chronic bronchitis, while the subjects in the two studies mentioned above had apparent bronchitis symptoms. The persistence of bronchitis might have damaged bronchial epithelial cells, leading to decreased production of SLPI from those cells.

The results of this study lead to the speculation that inflammation in small airways and alveolar destruction is associated with a rise in synthesis of SLPI in bronchiolar and/or alveolar epithelial cells. Unfortunately, transbronchial biopsy was not performed to observe the pathological changes in the peripheral airways. In reference to the previous literature, inflammation in peripheral airways precedes or is correlated with alveolar destruction $[21,22]$. Also, it is reported that the increase of SLPI-containing bronchiolar epithelial cells correlates with the degree of smallairway disease and that of parenchymal destruction [23], which agrees with these current findings. An increase in metaplastic SLPI-containing goblet cells and Clara cells might account for the rise of SLPI in BAL fluid since these cells are secretory [24], and the alveolar type II cell is another relevant cell type in this respect [4]. Therefore, the authors speculate the presence of some pathological changes in the peripheral airways may be a source of SLPI production in the subjects in this study. Elevation of protease inhibitor seems to be part of the local defence against inflammatory processes to minimize tissue damage.

Cigarette smoking induces an alteration in the protease/antiprotease balance with an increase in proteases and/or a reduction in antiproteases, leading to alveolar destruction $[25,26]$. However, it has long been debated which types of cells and/or which type of proteinases mainly contribute to the development of pulmonary emphysema. In a previous series of studies by the authors using a similar study design, the following were shown: 1) neutrophil-derived proteinases such as NE, neutrophil collagenase (matrix metalloproteinase (MMP)-8), gelatinase B (MMP-9), and a neutrophil-specific granule protein, human neutrophil lipocalin, are all elevated in BAL fluid from smokers who are developing pulmonary emphysema $[16,27]$; 2) interleukin-8, which is a potent chemoattractant/activator of neutrophils, is also increased in BAL fluid from those subjects [28]. All these results indicate a local neutrophil accumulation/ activation in peripheral airways and alveolar space in subjects with subclinical pulmonary emphysema. Conversely, in a previous study the authors found that the NE-inhibitory capacity of BAL fluid was elevated in smokers with emphysema compared with noncurrent smokers without emphysema, suggesting the upregulation of an "antiprotease shield" that neutralizes proteolytic enzymes in neutrophil-mediated 
inflammation [16]. There is a possibility that functional SLPI may partially account for the elastase inhibitory activity in BAL fluid, and is in line with the findings mentioned earlier.

Why is upregulation of the "antiprotease shield" not sufficient to prevent neutrophil-mediated lung destruction? The increased supply of SLPI to the "inflamed structure" appears to be insufficient to retain the normal architecture and function of the tissue because excessive SLPI goes along with the presence of alveolar destructive changes. The increased SLPI might be inactivated to inhibit the serine proteinases that contribute to the lung destruction. Thus, the molecular state of SLPI in BAL fluid was examined by Western blotting in this study. Local exposure of SLPI to oxidants and/or NE may lead to its degradation and thus the advantageous effect of SLPI may disappear in subjects who are developing pulmonary emphysema. A degraded form of SLPI has been previously reported in sputum from patients with cystic fibrosis $[9,29]$ and in bronchial lavage fluid from patients with diffuse panbronchiolitis [10]. Although such degradation was only detected in one subject with pulmonary emphysema, it is intriguing to speculate that the cleaved form of SLPI may contribute to disturbed function. Alternatively, other proteinases that could not be inhibited by SLPI might be key players for developing emphysema. Also the balance between proteinases/antiproteinases observed in BAL fluid may not reflect the microenvironments in which the destruction of extracellular matrix occurs.

It should be noted that it has been demonstrated for the first time, that human AM have the capacity to produce and release a significant amount of SLPI. Recently, it has been reported that murine AMs produce SLPI and that the level of SLPI mRNA expression is a determinant of species-related variation in the susceptibility to LPS-induced lung injury [5]. Therefore, the authors speculated whether the intersubject variation in the level of SLPI mRNA might be linked to the susceptibility to smokinginduced lung destruction. However, no significant difference in the levels of SLPI mRNA between the groups of smokers with and without pulmonary emphysema could be found. The amount of SLPI released from AM cultured for $24 \mathrm{~h}$ was larger in the subjects with subclinical emphysema than in the smoking controls, although it did not reach statistical significance. However, the releasability was not affected by co-culture with $\mathrm{CHX}$, indicating that the SLPI detected in the culture medium might have been due to the release of stored intracellular protein, not de novo protein synthesis. One explanation for this discrepancy may be that ex-vivo condition of culture in serum-less media is responsible for no active synthesis of SLPI in the macrophages. Another explanation is that the macrophages may have the capability of SLPI uptake that other cells such as bronchial epithelial cells produce and release, and also the capability of its release. It has been demonstrated that the AMs have such a mechanism for other proteins including neutrophil elastase [30]. It remains to be clarified how AM preserve SLPI intracellularly and what other functions SLPI in AM possess [31].
To conclude, the authors have demonstrated that the level of secretory leukocyte protease inhibitor is increased in peripheral airways and alveoli in subjects with subclinical emphysema compared to smoking controls without pulmonary emphysema. It has also been demonstrated that human alveolar macrophages have the capacity to produce and release secretory leukocyte protease inhibitor. However, the intersubject variation in the level of secretory leukocyte protease inhibitor messenger ribonuceic acid is not a determinant of the susceptibility to smoking-induced lung destruction.

\footnotetext{
Acknowledgements. The authors would like to thank Y. Kawakami (Konan Hospital, Sapporo, Japan) for his constructive comments and Y. Suzuki for her excellent technique in the experiments.
}

\section{References}

1. Thompson R, Ohlsson K. Isolation, properties, and complete amino acid sequence of human secretory leukocyte protease inhibitor, a potent inhibitor of leukocyte elastase. Proc Natl Acad Sci USA 1986; 83: 6692-6696.

2. Franken C, Kramps JA, Meyer CJ, Dijkman JH. Localization of a low molecular weight protease inhibitor in the respiratory tract. Bull Eur Physiopathol Respir 1980; 16: Suppl., 231-236.

3. Mooren HW, Kramps JA, Franken C, Meijer CJ, Dijkman JA. Localisation of a low-molecular-weight bronchial protease inhibitor in the peripheral human lung. Thorax 1983; 38: 180-183.

4. Sallenave JM, Silva A, Marsden ME, Ryle AP. Secretion of mucus proteinase inhibitor and elafin by Clara cell and type II pneumocyte cell lines. Am J Respir Cell Mol Biol 1993; 8: 126-133.

5. Jin FY, Nathan C, Radzioch D, Ding A. Secretory leukocyte protease inhibitor: a macrophage product induced by and antagonistic to bacterial lipopolysaccharide. Cell 1997; 88: 417-426.

6. Fryksmark U, Prellner T, Tegner H, Ohlsson K. Studies on the role of antileukoprotease in respiratory tract diseases. Eur J Respir Dis 1984; 65: 201-209.

7. Kida K, Mizuuchi T, Takeyama K, et al. Serum secretory leukoprotease inhibitor levels to diagnose pneumonia in the elderly. Am Rev Respir Dis 1992; 146: $1426-1429$.

8. Sallenave JM, Donnelly SC, Grant IS, Robertson C, Gauldie J, Haslett C. Secretory leukocyte proteinase inhibitor is preferentially increased in patients with acute respiratory distress syndrome. Eur Respir $J$ 1999; 13: 1029-1036.

9. Sallenave JM, Si-Ta har M, Cox G, Chignard M, Gauldie J. Secretory leukocyte proteinase inhibitor is a major leukocyte elastase inhibitor in human neutrophils. J Leukoc Biol 1997; 61: 695-702.

10. Kouchi I, Yasuoka S, Ueda Y, Ogura T. Analysis of secretory leukocyte protease inhibitor (SLPI) in bronchial secretions from patients with hypersecretory respiratory diseases. Tokushima J Exp Med 1993; 40: 95-107.

11. Hill AT, Bayley D, Stockley RA. The interrelationship 
of sputum inflammatory markers in patients with chronic bronchitis. Am J Respir Crit Care Med 1999; 160: 893-898.

12. Kramps JA, Te Boekhorst AH, Fransen JA, Ginsel LA, Dijkman JH. Antileukoprotease is associated with elastin fibers in the extracellular matrix of the human lung. An immunoelectron microscopic study. Am Rev Respir Dis 1989; 140: 471-476.

13. Rice WG, Weiss SJ. Regulation of proteolysis at the neutrophil-substrate interface by secretory leukoprotease inhibitor. Science 1990; 249: 178-181.

14. Lucey EC, Stone PJ, Ciccolella DE, et al. Recombinant human secretory leukocyte-protease inhibitor: in vitro properties, and amelioration of human neutrophil elastase-induced emphysema and secretory cell metaplasia in the hamster. J Lab Clin Med 1990; 115: 224-232.

15. Wang Z, Zheng $\mathrm{T}$, Zhu Z, et al. Interferon gamma induction of pulmonary emphysema in the adult murine lung. J Exp Med 2000; 192: 1587-1600.

16. Yoshioka A, Betsuyaku T, Nishimura M, Miyamoto $\mathrm{K}$, Kondo T, Kawakami Y. Excessive neutrophil elastase in bronchoalveolar lavage fluid in subclinical emphysema. Am J Respir Crit Care Med 1995; 152: 2127-2132.

17. Rennard S, Ghafouri M, Thompson AB, et al. Fractional processing of sequential bronchoalveolar lavage to separate bronchial and alveolar samples. $\mathrm{Am}$ Rev Respir Dis 1990; 141: 208-217.

18. Betsuyaku T, Yoshioka A, Nishimura M, Miyamoto K, Kondo T, Kawakami Y. Neutrophil elastase associated with alveolar macrophages from older volunteers. Am J Respir Crit Care Med 1995; 151: 436-442.

19. Betsuyaku T, Griffin GL, Watson MA, Senior RM. Laser capture microdissection and real-time quantitative RT-PCR of terminal bronchiolar epithelium after intratracheal bleomycin. Am J Respir Cell Mol Biol 2001; 25: 278-284.

20. Stetler G, Brewer MT, Thompson RC. Isolation and sequence of a human gene encoding a potent inhibitor of leukocyte proteases. Nucleic Acids Res 1986; 14 : 7883-7896.

21. Saetta M, Ghezzo H, Kim WD, et al. Loss of alveolar attachments in smokers. A morphometric correlate of lung function impairment. Am Rev Respir Dis 1985; 132: 894-900.

22. Cosio MG, Hale KA, Niewoehner DE. Morphologic and morphometric effects of prolonged cigarette smoking on the small airways. Am Rev Respir Dis 1980; 122: 265-271.

23. Willems LNA, Kramps JA, Stijnen T, Sterk PJ, Weening JJ, Dijkman JH. Antileukoproteasecontaining bronchiolar cells. Am Rev Respir Dis 1989; 139: 1244-1250.

24. De Walter R, Willems LN, Van Muijen GN, et al. Ultrastructural localization of bronchial antileukoprotease in central and peripheral human airways by a gold-labeling technique using monoclonal antibodies. Am Rev Respir Dis 1986; 133: 882-890.

25. Janoff A. Elastase and emphysema. Current assessment of the protease-antiprotease hypothesis. Am Rev Respir Dis 1985; 132: 417-433.

26. Senior RM, Anthonisen N. Advances in pulmonary biology and medicine: chronic obstructive pulmonary disease. Am J Respir Cell Mol Biol 1998; 157: S139S147.

27. Betsuyaku T, Nishimura M, Takeyabu $\mathrm{K}$, et al. Neutrophil granule proteins in bronchoalveolar lavage fluid from subjects with subclinical emphysema. Am J Respir Crit Care Med 1999; 159: 1985-1991.

28. Tanino M, Betsuyaku T, Takeyabu K, et al. Increased levels of interleukin-8 in BAL fluid from smokers susceptible to pulmonary emphysema. Thorax 2002 (in press).

29. Vogelmeier C, Hubbard RC, Fells GA, et al. Antineutrophil elastase defense of the normal human respiratory epithelial surface provided by the secretory leukoprotease inhibitor. J Clin Invest 1991; 87: 482488.

30. Campbell EJ, White RR, Senior RM, Rodriquez RJ, Kuhn C. Receptor-mediated binding and internalization of leukocyte elastase by alveolar macrophages in vitro. J Clin Invest 1979; 64: 824-833.

31. Jin F, Nathan CF, Radzioch D, Ding A. Lipopolysaccharide-related stimuli induce expression of the secretory leukocyte protease inhibitor, a macrophagederived lipopolysaccharide inhibitor. Infec Immun 1998; 66: 2447-2452. 